\title{
RARE CASE REPORT OF HEMIMEGALENCEPHALY PRESENTING WITH ABNORMAL MOVEMENTS \& SPASTICITY IN A CASE OF NEUROFIBROMATOSIS TYPE I
}

\author{
Rini Palve1, V. D. Aironi2 ${ }^{2}$ Abhay Gursale ${ }^{3}$, Shishir Kumar, Ashutosh Chitnis ${ }^{5}$
}

\section{HOW TO CITE THIS ARTICLE:}

Rini Palve, V. D. Aironi, Abhay Gursale, Shishir Kumar, Ashutosh Chitnis. "Rare Case Report of Hemimegalencephaly Presenting with Abnormal Movements \& Spasticity in a Case of Neurofibromatosis Type I". Journal of Evolution of Medical and Dental Sciences 2015; Vol. 4, Issue 63, August 06; Page: 11074-11079,

DOI: $10.14260 /$ jemds/2015/1595

ABSTRACT: Hemimegalencephaly is a congenital brain malformation characterized by unilateral enlargement of the cerebral hemisphere. Clinically it is associated with hemiparesis, seizures and developmental delays. It is often an isolated finding but can be occasionally associated with any syndromes.[1] The case patient we are discussing presented at the age of 40 years with peripheral neurological symptoms, past history of few episodes of seizures and no mental retardation due to which the patient was not diagnosed in early childhood. The patient was apparently symptomless till 20 years of age after which he started developing neurofibromas. Hemimegalencephaly along with neurofibromatosis- 1 is a rare entity.

KEYWORDS: Hemimegalencephaly, Neurofibromatosis- type 1, NF-1.

INTRODUCTION: Hemimegalencephaly or unilateral megalencephaly is a severe, rare and congenital malformation of cortical development, characterized by enlargement of all or parts of a cerebral hemisphere. The affected hemisphere may have focal or diffuse neuronal migration defects, with areas of polymicrogyria, pachygyria, and heterotopia. The etiology of this condition is unknown, though it is speculated that it involves abnormalities of neuronal differentiation and cell migration in a single hemisphere. The association of Hemimegalencephaly with Neurofibromatosis-1 is a very unusual presentation. Magnetic resonance imaging is the imaging technique of choice for diagnosis of this condition. ${ }^{[2,3]}$ We report the following case to illustrate the MR imaging features of this uncommon but major congenital malformation of the brain.

CASE REPORT: A 40 year old male resident of Navi Mumbai came to the hospital pain in neck, with rigidity and spasticity of upper limb muscles. There was associated abnormal movement of right arm. There is past history of seizures in the patient in early childhood, which has subsided in the recent years. The patient gave history of multiple soft swellings, mobile and non-tender over the skin of the upper back region. The patient also had multiple light brown spots in his axillae which measured around $1.5-2 \mathrm{~cm}$ in size (Café au lait spots). No family history was noted. On general and systemic examination patient was:

- Conscious co-operative and found to have pallor.

- Tone increased in right upper limb. power of 5/5 in both lower limbs and left upper limb across all joints except at right shoulder, elbow wrist and small joints where it was 4/5.

- Mild spasticity present.

- Reflexes were exaggerated at right triceps and supinator. 
- Intention tremors present on right side of body. Dysdiadokinesia present on left side of body. Finger nose test abnormal on left side.

- No sensory loss noted.

Non-contrast and post contrast MRI scan was performed. MRI T1 and T2 weighted images showed a large left cerebral hemisphere with large left hemi cranium which has deeper cranial fossa on left side as compared to right. There is e/o polymicrogyria of left cerebral hemisphere especially in left occipital lobe with dysplastic large left cerebral hemisphere and relatively thicker white matter in left hemisphere as compared to right side (Figure 3). On T2 weighted images there is dilatation of left lateral ventricle especially the temporal horn (Figure 1). The left cerebellar hemisphere is also dysplastic and large with widened cerebellar fissures and folia (Figure 2). Falx cerebri is deviated to left side. The cerebral sulcal pattern is normal on right side. The Corpus callosum and Brainstem also appears normal (Figure $4 \mathrm{a}$, b).No abnormal post contrast enhancement is seen in brain parenchyma and related meninges.

Figure 1: Axial T2WI at the level of body of lateral ventricles show dilatation of left lateral ventricle especially the temporal horn. Also Falx cerebri deviated to right side.

Figure 2: Axial T2WI at the level of pons shows dysplasia and enlargement of cerebellar hemisphere with widened cerebellar fissures and folia.

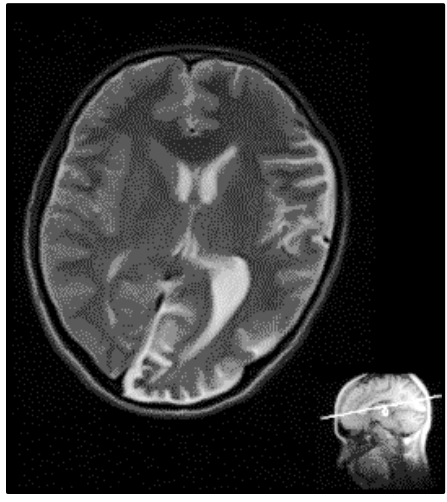

Fig. 1

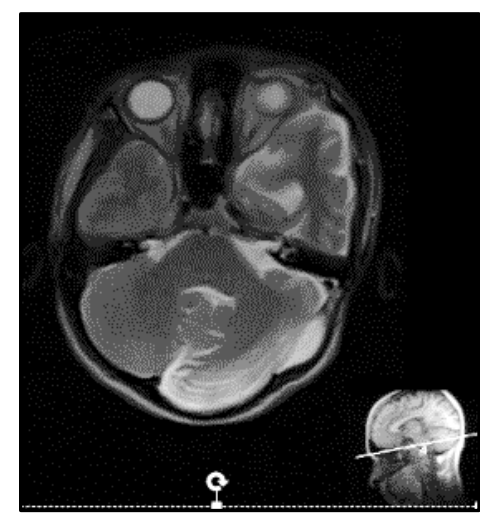

Fig. 2

Figure 3: Axial T2WI at the level of basal ganglia shows enlarged left cerebellum and has a deeper cranial fossa on left side as compared to right. There is e/o polymicrogyria of left cerebral hemisphere especially in left occipital lobe.

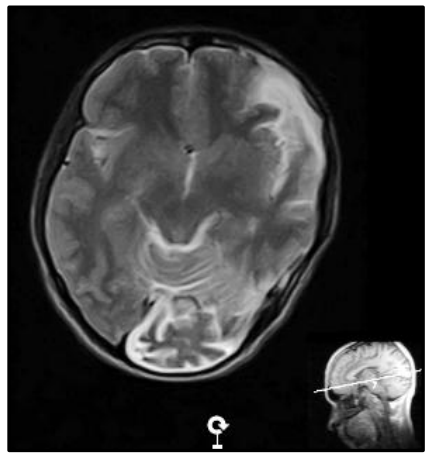

Fig. 3 


\section{CASE REPORT}

Figure 4a, b: Mid-sagittal T1WI and FLAIR coronal shows normal corpus callosum and brainstem.

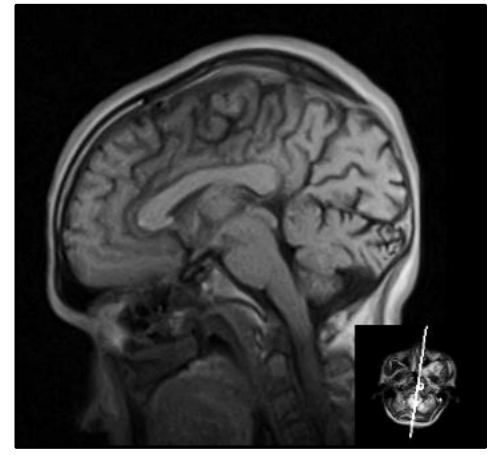

Fig. 4a

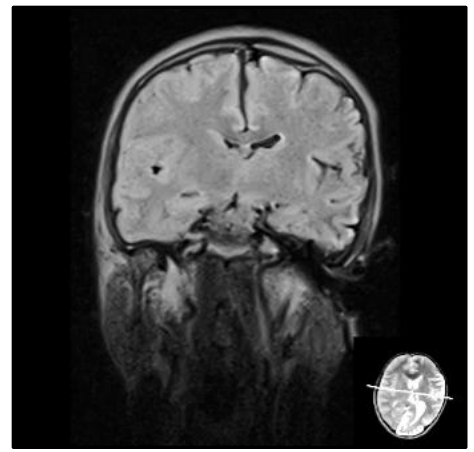

Fig. 4b

In view of history of neurofibromatosis, neck pain and spasticity and of right hand, with cerebellar signs further evaluation with MRI brainstem and cervical spine with post contrast was done.

On T2 weighted and STIR images there is a lobulated hyperintense extra-medullary, extradural lesion measuring $2.5 \times 1.6 \mathrm{~cm}$ in size located along the widened $\mathrm{C} 1-\mathrm{C} 2$ inter-vertebral neural foramen on right side with dumb-bell shape and extra-foraminal extension measuring $15 \times 15 \mathrm{~mm}$ in size. There is similar nature dumb-bell shaped extra-dural lesions, one at left C3-C4 inter-vertebral neural foramen which is expanded, and measuring $2.4 \times 1.8 \mathrm{~cm}$ in size with similar extra-foraminal component. There are similar small inter-vertebral neural foraminal neurofibromas at C1-C2 level on left side, C2-C3 level on both sides and C3-C4 on right side, largest measuring 17x13 mm in size. Few are also seen at C5-C6 inter-vertebral neural foramen on left side, one in subcutaneous region of nape of neck at C7-D1 vertebral level, measuring 14x10mm. The right sided lesion at C1-C2 vertebral level is causing compression of cord because of its intra-spinal component, however cord signal is normal. Similarly there is antero-lateral compression of cord by lesion at C4-C5 level on left side.

On post contrast study these extra medullary cervical spinal lesions show homogenous enhancement suggestive of multiple cervical spinal neurofibromas.

Figure 5a, b: On Axial and Coronal T2WI there is a lobulated hyperintense, extra-medullary, extradural lesion located along the widened C1-C2 inter-vertebral neural foramen on right side with dumb-bell shape and extra-foraminal extension. c: On STIR image this lesion shows no suppression confirming Neurofibroma.

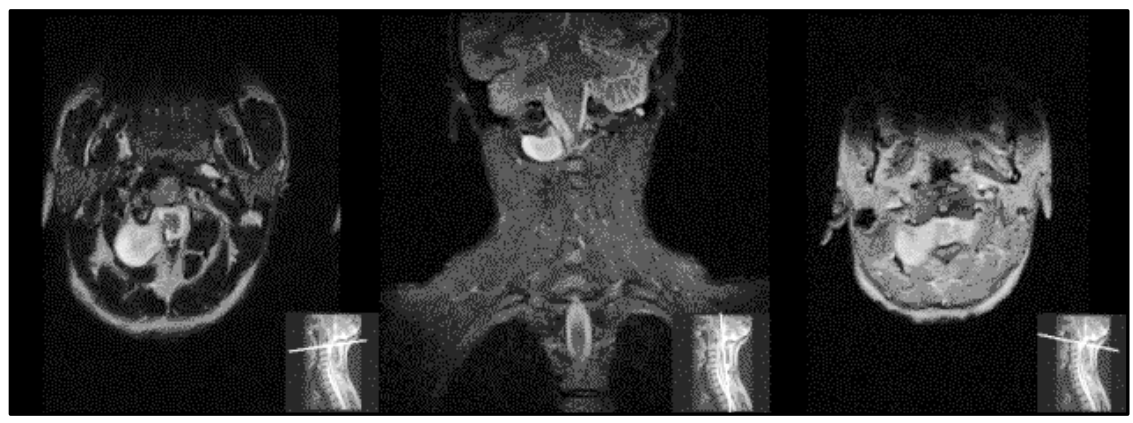

Fig. 5a \& b 


\section{CASE REPORT}

Figure 6: On Coronal T2WI there is antero-lateral compression of cord by lesion at C4-C5 level on left side.

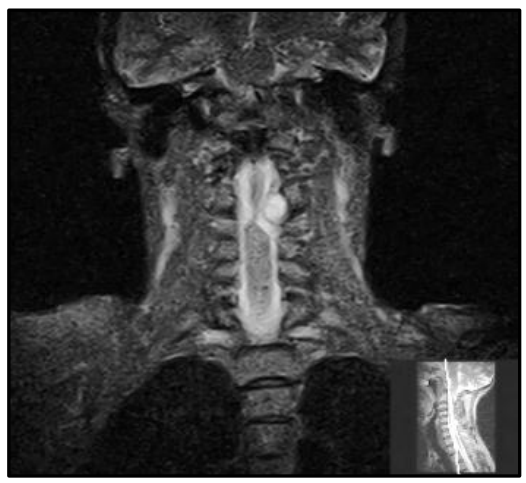

Fig. 6

Figure 7 a, b: On Axial and Coronal T2WI there is another dumb-bell shaped extra-dural lesion, one at left C3-C4 inter-vertebral neural foramen which is expanded, and measuring $2.4 \times 1.8 \mathrm{~cm}$ in size with similar extra foraminal component. c: On STIR image this lesion shows no suppression confirming Neurofibroma.

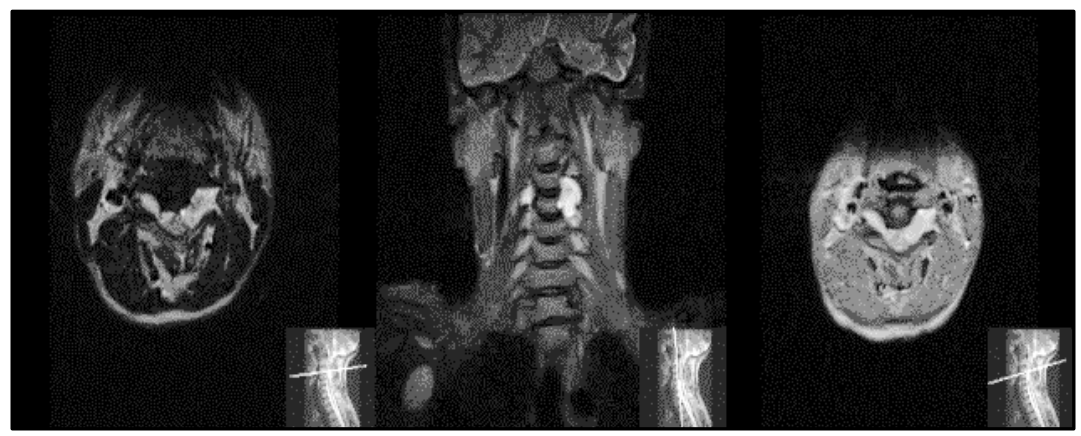

Fig. 7a \& b

DISCUSSION: Hemimegalencephaly is a rare congenital disorder in which there is hamartomatous overgrowth of all or part of a cerebral hemisphere.

Our patient presented with hemimegalencephaly along with Neurofibromatosis- 1 , which is a rare entity and very few of such cases have been documented in literature. The affected hemisphere may have focal or diffuse neuronal migration defects, with areas of polymicrogyria, pachygyria, and heterotopia.[3,4]

There are three types of Hemimegalencephaly.[2,5]

The isolated form occurs as a sporadic disorder without hemicorporal hypertrophy or cutaneous or systemic involvement.

The syndromic form is associated with other diseases and may occur as hemihypertrophy of part or all of the ipsilateral body. It has been described in patients with epidermal nevus syndrome, Proteus syndrome, Neurofibromatosis type 1, Hypermelanosis of Ito, Klippel-Trenaunay syndrome, and Tuberous Sclerosis.

The third and least common type is total hemimegalencephaly, in which there is also enlargement of the ipsilateral half of the brainstem and cerebellum. 
This patient appears to have mixed megalencephaly with both type two and three as there is both association with neurofibromatosis-1 and involvement of cerebellum.

Males and females are equally affected.

Epilepsy is the most frequent neurologic manifestation, occurring in greater than $90 \%$ of patients.

Although progressive hemiplegia and hemianopia are common, some patients do not have focal motor deficits.

In this case there is presentation of hemimegalencephaly at later age.

Involvement of cerebrum, cerebellum and spinal cord at multiple levels.

Clinically it presented with weakness, abnormal movements of right hand, and seizures.

Neurofibromatosis-1 or Von Recklinghausen's disease is most common cause of neurofibromatosis overall.

Its incidence is 1 in 3000 live births.

Hallmark of NF-1 are café au lait spots and neurofibromas. One half of the patients are familial. Most common tumour is optic nerve glioma in $14 \%$ cases. Presenting as gradual diminution of vision and increasing proptosis.

The mutation of NF-1 gene chr. 17q11.2 whose product is neurofibromin expressed in many organs like brain, kidney, spleen and thymus. It belongs to family of GT Pases that stimulate intrinsic GT Pase activity in RASp21 family that activates a number of signaling pathways that includes

- M TOR.

- SCF/C-KIT.

- MAP KINASE.[6]

The following are features of neurofibromatosis and two or more are required to make diagnosis:[7]

- Café - au-lait spots- more than 6.

- Two or more neurofibromas or one plexiform neurofibroma.

- Optic nerve glioma.

- Osseous lesions if present appear during first year.

- Sphenoid wing dysplasia.

- Two or more iris hamartomas (Lisch nodules).

- Axillary inguinal freckling.

- Primary relative with NF-1.

\section{REFERENCES:}

1. Anne G. Osborn (2013). Osborn's brain: Imaging, Pathology and Anatomy. Canada: AMIRSYS.

2. Broumandi DD, Hayward UM, Benzian JM et-al. Best cases from the AFIP: hemimegalencephaly. Radiographics. 24 (3): 843-8.

3. N. Satoa, A. Yagishitac, H. Obad, Y. Mikie, Y. Nakataa, F. Yamashitaf, K. Nemotog, K. Sugaib and M. Sasakib; AJNR: Hemimegalencephaly: A Study of Abnormalities Occurring Outside the Involved Hemisphere. April 2007.

4. Barkovich AJ, Chuang SH. Unilateral megalencephaly: correlation of MR imaging and pathologic characteristics. AJNR Am J Neuroradiol1990; 11: 523-31. 


\section{CASE REPORT}

5. Abdel Razek AA, Kandell AY, Elsorogy LG et-al. Disorders of cortical formation: MR imaging features. AJNR Am J Neuroradiol. 2009; 30 (1): 4-11.

6. Brad T. Tinkle, Elizabeth K. Schorry, David N. Franz, Kerry R. Crone and Howard M. Seal; AJMG: epidemiology of hemimegalencephaly: case series and review. Vol 139A, Dec 2005.

7. Pediatric Neuroradiology: Brain. Head, Neck and Spine by Paolo Tortori-Donati, Andrea Rossi.

\section{AUTHORS:}

1. Rini Palve

2. V. D. Aironi

3. Abhay Gursale

4. Shishir Kumar

5. Ashutosh Chitnis

\section{PARTICULARS OF CONTRIBUTORS:}

1. Resident, Department of Radiology, MGM Medical College \& Hospital.

2. Associate Professor, Department of Radiology, MGM Medical College \& Hospital.

3. Professor, Department of Radiology, MGM Medical College \& Hospital.

FINANCIAL OR OTHER

COMPETING INTERESTS: None
4. Resident, Department of Radiology, MGM Medical College \& Hospital.

5. Associate Professor, Department of Radiology, MGM Medical College \& Hospital.

\section{NAME ADDRESS EMAIL ID OF THE CORRESPONDING AUTHOR:}

Dr. Rini Palve, 603-Dwarka APTS,

Thanawala Lane, Vile Parle (East), Mumbai-400057.

E-mail: rinz.palve@gmail.com

Date of Submission: 13/06/2015. Date of Peer Review: 15/06/2015. Date of Acceptance: 13/07/2015. Date of Publishing: 06/08/2015. 